\begin{tabular}{l|c|c|c|c|} 
DOI: http://dx.doi.org/10.21276/ap.covid19.2021.10.1.18 \\
Annals of Phytomedicine: An International Journal \\
http://www.ukaazpublications.com/publications/index.php \\
Print ISSN : 2278-9839
\end{tabular}

\title{
Prospection of antiviral compounds from forest plants under ongoing SARS-COV-2 pandemic
}

Natchiappan Senthilkumar», Ramasamy Sumathi and Devaraj Suresh Babu Institute of Forest Genetics and Tree Breeding, Coimbatore-641002, Tamil Nadu, India

\begin{tabular}{|c|c|}
\hline Article Info & Abstract \\
\hline $\begin{array}{l}\text { Article history } \\
\text { Received } 10 \text { April } 2021 \\
\text { Revised } 29 \text { May } 2021 \\
\text { Accepted } 30 \text { May } 2021 \\
\text { Published Online } 30 \text { June } 2021\end{array}$ & $\begin{array}{l}\text { The COVID-19 pandemic is due to the spread of SARS-CoV-2, a virulent infectious coronavirus which } \\
\text { created severe threats to the public health systems and global socioeconomic impact. It spreads over } \\
221 \text { countries and territories around the world and has reported a total of } 130,954,934 \text { confirmed } \\
\text { cases with a death toll of } 2,853,007 \text {. An indepth understanding of SARS-CoV- } 2 \text { virus in terms of structure, } \\
\text { variants, mechanism of infection, spread and impacts is needed to develop strategies to eradicate it. It }\end{array}$ \\
\hline $\begin{array}{l}\text { Keywords } \\
\text { COVID } \\
\text { SARS-CoV } \\
\text { Herbal medicines } \\
\text { Virus } \\
\text { Antiviral drugs }\end{array}$ & $\begin{array}{l}\text { Delhi and Chennai. Since historic epidemics, most of the antiviral medicines are mainly developed } \\
\text { based on medicinal plants with the aid of ethnobotanical records. Conventional medicine along with } \\
\text { dietary therapy could be a complementary therapeutic measure to prevent and manage SARS-CoV-2 } \\
\text { infections. Herbal drugs from medicinal and aromatic plants are major source for the development of } \\
\text { novel antiviral drugs. Exploration of plants with numerous bioactive compounds of therapeutic } \\
\text { importance remains mostly scanty. Identifying potential natural plant sources constitute an alternate } \\
\text { to contain and prevent SARS-CoV-2 infection either by being a viricidal or by boosting the immune } \\
\text { system is need of the hour. In order to prevent and contain the severe respiratory infections associated } \\
\text { with the COVID } 19 \text { pandemic in the absence of potential medicines against the SARS-CoV-2 virus, search } \\
\text { for antiviral compounds from natural resources gains importance. This article aimed to provide } \\
\text { comprehensive list of plants and their active compounds of antiviral properties which would pave a } \\
\text { way to develop herbal drug to prevent and contain SARS-CoV-2 infection. }\end{array}$ \\
\hline
\end{tabular}

\section{Introduction}

The exponential spread of the novel coronavirus named severe acute respiratory syndrome coronavirus 2 (SARS-CoV-2), caused a serious global threat to human health. Severe acute respiratory syndrome (SARS) is a respiratory illness caused by SARS-CoV-2 (Drosten et al., 2003; Ksiazek et al., 2003; Peiris et al., 2003b; Poutanen et al., 2003). This febrile respiratory illness was initially described in early 2003 (Chan-Yeung and Yu, 2003; Donnelly et al., 2003; Lee et al., 2003; Peiris et al., 2003a; Tsang et al., 2003). The potential to cause life-threatening respiratory failure and rapid transmission placed SARS-CoV-2 in public health emergency of international concern (PHEIC) list (Al-Qahtani, 2020). In the last two decades, the world has faced three important outbreaks of very pathogenic CoVs, including the emergence of SARS-CoV between 2002 and 2003, Middle East Respiratory Syndrome (MERS-CoV) in the year 2012 till date and now COVID-19 is the $3^{\text {rd }}$ deadliest coronavirus pandemic. The coronavirus disease 2019 (COVID-19) pandemic (previously known as 2019-nCoV) was first discovered in the city of Wuhan, China, at the end of December 2019. In a very short period, an outbreak of apparent idiopathic pneumonia had become the COVID-19 pandemic and countries

Corresponding author: Dr. N. Senthilkumar

Scientist F, Institute of Forest Genetics and Tree Breeding, Coimbatore641002, Tamil Nadu, India

E-mail: senthilnk@icfre.org

Tel.: +91-9629160703

Copyright () 2021 Ukaaz Publications. All rights reserved.

Email: ukaaz@yahoo.com; Website: www.ukaazpublications.com worldwide are comprehensively trying to find preventative measures or cure against the acute resolving disease COVID-19. This pandemic situation warrants us to develop novel antiviral drugs immediately to control and prevent the spread of SARS-CoV-2.

India predominantly relied on plant-based medications under different domain names like Ayurveda, Siddha, Unani, etc. Though, the advent of allopathic medicines has cornered the prevalence of plant-based treatments, the current pandemic emphasizes the need for revisiting those plants and studying those using advanced tools and approaches. Technological interventions are the need-of-thetime to dissect the medicinal value of plants for identifying suitable phytocompounds that could serve as potential molecules in treating SARS-CoV-2. In this present scenario, exploration of plants with bioactive molecules of antiviral property for the development of novel drug is much needed. Several antiviral active compounds from medicinal plants against some notable viral pathogens including coronavirus $(\mathrm{CoV})$, coxsackie virus (CV), dengue virus (DENV), entero virus 71 (EV71), hepatitis B virus (HBV), hepatitis C virus (HCV), herpes simplex virus, human immunodeficiency virus (HIV), influenza virus, measles virus (MV), and respiratory syncytial virus (RSV) have been discovered, however, nature and composition of those plants and their mode of actions are not available for drug development. The age-old antimalarial drug chloroquine (Cq), introduced in 1945 and its analogue hydroxychloroquine (Hcq) could be potent therapeutic agents against COVID-19 (Tripathy et al., 2020). Quinine an alkaloid obtained from the bark of Cinchona officinalis has been used in the treatment of malaria since the 1960s (Achan et al., 2011). In SARS-CoV-2, Hcq in combination with 
azithromycin found to be more effective in reducing the viral load (Gautreta et al., 2020). Similarly, glycyrrhizin, a saponin isolated from Glycyrrhiza glabra roots is reported to be effective against SARS-CoV by inhibiting viral replication (Cinatl et al., 2003b). As an RNA virus, 2019-nCoV may have the same functional proteins to process virus replication and assembly to human immunodeficiency virus (HIV). As a result, HIV protease inhibitors may also be effective for 2019-nCov. Currently, the combination of lopinavir/ritonavir (LPV/R), which has been proven effective in SARS-CoV and MERS-CoV, has been recommended for treatment in 2019-nCoV. It is also reported that around 35 drugs and vaccines are under clinical trials for amelioration of COVID-19. AYUSH,
Ministry of Health, GOI, New Delhi has recommended various traditional formulations for both preventive and symptomatic management of COVID-19 (Table 1) with add on interventions to conventional care from Ayurvedha, Siddha, Unani, and Homeopathy. There are around 25 plant species reported to have inhibitory activity on ACE, IL and other proteins such as Transmembrane protease, serine 2 (TMPRSS2); 3-chymotrypsin-like protease (3CLpro); spike, RNA-dependent RNA polymerase (RdRp), and papain like protease (PLpro) which would lead to develop drug for SARS-CoV-2. This review throws the state of knowledge on the antiviral compounds from medicinal plants under ongoing SARSCOV-2 pandemic.

Table 1: This table depicts the Indian medicinal plants and its usage provided by the AYUSH, Government of India as a therapeutic approach for COVID-19

\begin{tabular}{|c|c|c|c|c|c|c|}
\hline $\begin{array}{l}\text { Indian medicinal } \\
\text { plant }\end{array}$ & $\begin{array}{l}\text { Form of } \\
\text { extract }\end{array}$ & Trade name & $\begin{array}{l}\text { Indian } \\
\text { traditional } \\
\text { medical } \\
\text { practice }\end{array}$ & Preparation & $\begin{array}{l}\text { Recommended } \\
\text { usage }\end{array}$ & Effective against \\
\hline \multicolumn{7}{|c|}{ Preventive and prophylactic } \\
\hline Tinospora cordifolia & Aqueous & Samshamanivati & Ayurveda & $\begin{array}{l}\text { Samshamanivati } \\
500 \mathrm{~g} \text { with } \\
\text { warm water }\end{array}$ & $\begin{array}{l}\text { Twice a day } \\
\text { for } 15 \text { days }\end{array}$ & Chronic fever \\
\hline $\begin{array}{l}\text { Andrographis } \\
\text { paniculata }\end{array}$ & Aqueous & Nilavembukudineer & Siddha & $\begin{array}{l}\text { Nilavembukudineer } \\
60 \mathrm{ml} \text { decoction }\end{array}$ & $\begin{array}{l}\text { Twice a day } \\
\text { for } 14 \text { days }\end{array}$ & Fever and cold \\
\hline Cydonia oblonga & Aqueous & Behidanaunnab & Unani & $\begin{array}{l}\text { Behidana-3 g } \\
\text { Unnab-5 Nos }\end{array}$ & $\begin{array}{l}\text { Twice a day } \\
\text { for } 14 \text { days }\end{array}$ & $\begin{array}{l}\text { Antioxidant, } \\
\text { immunemodulatory } \\
\text { antiallergic, smooth } \\
\text { muscle relaxant, } \\
\text { anti-influenza } \\
\text { activity. }\end{array}$ \\
\hline $\begin{array}{l}\text { Zizyphus jujube } \\
\text { Cordia myxa }\end{array}$ & Sapistan & & & $\begin{array}{l}\text { Sapistan }-9 \text { Nos } \\
\text { Boil these } 3 \text { in } \\
250 \mathrm{ml} \text { water, } \\
\text { boil it until it } \\
\text { remains half and } \\
\text { filter it. }\end{array}$ & & \\
\hline Arsenicum album 30 & Tablet & $\begin{array}{l}\text { Arsenicum } \\
\text { album } 30\end{array}$ & Homeopathy & & $\begin{array}{l}\text { Daily once in } \\
\text { empty stomach } \\
\text { for } 3 \text { days (should } \\
\text { be presented after } \\
1 \text { month till the } \\
\text { infection persist). }\end{array}$ & $\begin{array}{l}\text { Effective against } \\
\text { SARS-CoV-2, } \\
\text { immunemodulator. }\end{array}$ \\
\hline \multicolumn{7}{|c|}{ Symptomatic management for COVID-19 } \\
\hline Ayush-64 & Tablet & - & Ayurveda & - & $\begin{array}{l}2 \text { tablets } \\
\text { twice a day }\end{array}$ & $\begin{array}{l}\text { Respiratory } \\
\text { infection }\end{array}$ \\
\hline Agastya haritaki & Powder & $\begin{array}{l}\text { Agasthya } \\
\text { rasayanam }\end{array}$ & Ayurveda & $\begin{array}{l}5 \text { gm in warm } \\
\text { water }\end{array}$ & Twice a day & $\begin{array}{l}\text { Upper respiratory } \\
\text { infection }\end{array}$ \\
\hline Anuthaila & Oil & Sesame oil & Ayruveda & - & $\begin{array}{l}2 \text { drops in each } \\
\text { nostril daily } \\
\text { morning }\end{array}$ & $\begin{array}{l}\text { Respiratory } \\
\text { infection }\end{array}$ \\
\hline Adathodai manapagu & Aqueous & $\begin{array}{l}\text { Adathodai } \\
\text { manapagu }\end{array}$ & Siddha & - & $\begin{array}{l}10 \mathrm{ml} \text { twice } \\
\text { a day }\end{array}$ & Fever \\
\hline Bryonia alba & Tablet & Bryonia & Homeopathy & - & - & $\begin{array}{l}\text { Reducing lung } \\
\text { inflammation }\end{array}$ \\
\hline
\end{tabular}




\begin{tabular}{|c|c|c|c|c|c|c|}
\hline Rhustoxicodendron & Tablet & Rhustox & Homeopathy & - & - & Viral infection \\
\hline Atropa belladonna & Tablet & Belladonna & Homeopathy & - & - & $\begin{array}{l}\text { Asthma and } \\
\text { chronic lung } \\
\text { diseases. }\end{array}$ \\
\hline $\begin{array}{l}\text { Bignonia } \\
\text { sempervirens }\end{array}$ & Tablet & Geisemium & Homeopathy & - & - & Asthma \\
\hline $\begin{array}{l}\text { Eupatorium } \\
\text { perfoliatum }\end{array}$ & Tablet & $\begin{array}{l}\text { Eupatorium } \\
\text { perfoliatum }\end{array}$ & Homeopathy & - & - & $\begin{array}{l}\text { Respiratory } \\
\text { symptoms }\end{array}$ \\
\hline \multicolumn{7}{|c|}{ Add on interventions to the conventional care } \\
\hline Vishasura kudineer & Tablet & $\begin{array}{l}\text { Polyherbal } \\
\text { formulation }\end{array}$ & Siddha & Decoction $60 \mathrm{ml}$ & Twice a day & Fever \\
\hline Kabasura kudineer & Tablet & $\begin{array}{l}\text { Polyherbal } \\
\text { formulation }\end{array}$ & Siddha & Decoction $60 \mathrm{ml}$ & Twice a day & \\
\hline
\end{tabular}

(Ref: AYUSH Ministry of Health Corona Advisory - D.O. No. S. 16030/18/2019 - NAM).

\section{Genomic organization and virus structure}

Coronavirus (COVs) are encased in a positive stranded RNA that comes into the coronavirinae subfamily. In addition, the genetic material is surrounded by nucleocapsid proteins in the nucleus and envelope that contain four proteins, such as spike proteins, envelope proteins, and membrane proteins. The genome of the $\mathrm{CoVs}$ range is long from 26 to 32 kilobase, which is perhaps the largest known RNA virus.

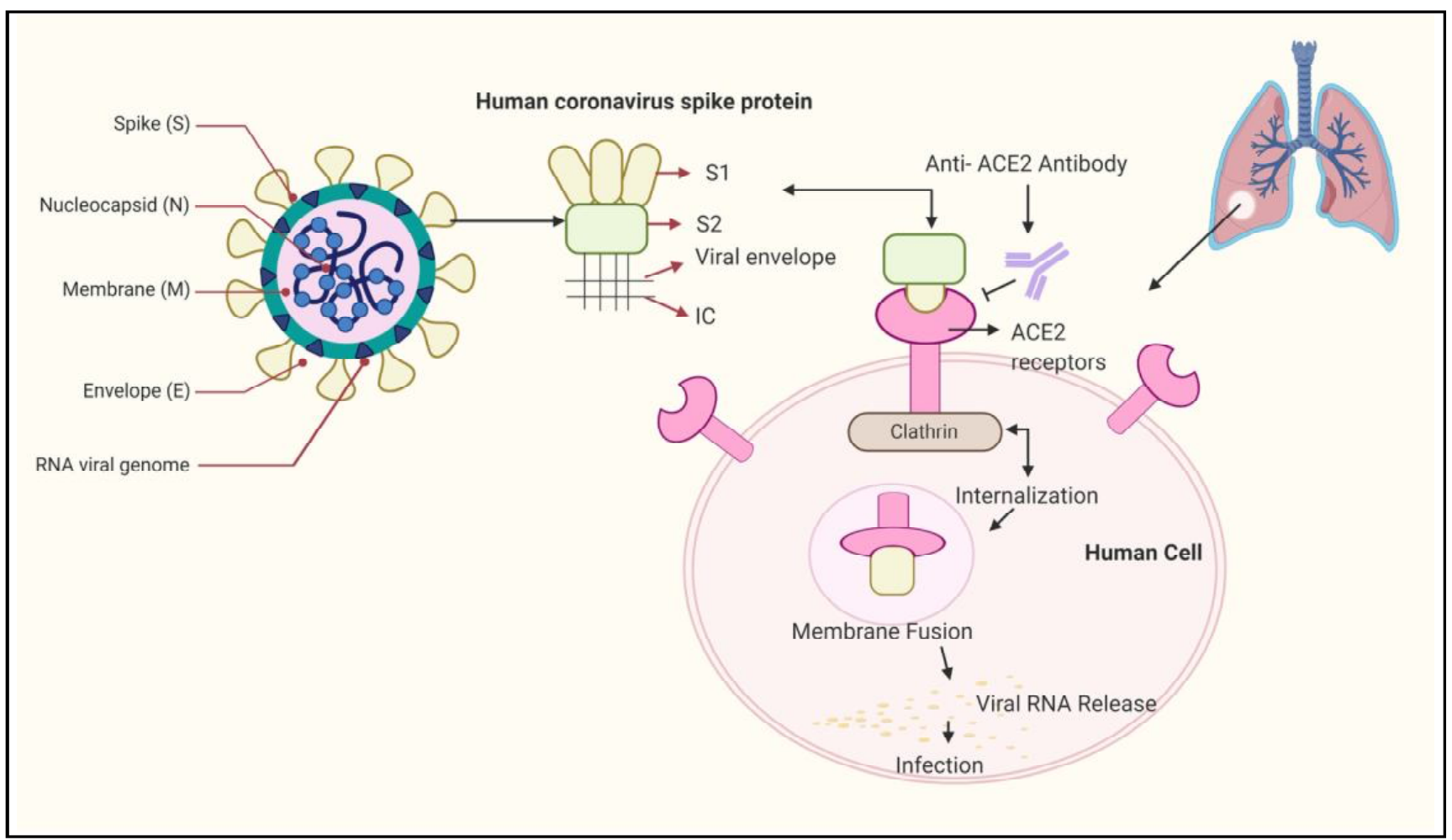

Figure 1: Mode of action of coronavirus (CoV). (Source: Vellingiri et al., 2020).

Among the viral structure, the S protein has a major role in binding the virus to the host receptor cells. S protein has two subunits which are the S1 receptor-binding subunit and S2 the membrane fusion subunit; where the earlier one attached itself to the ACE2 receptor of the human host cell and the $\mathrm{S} 2$ subunit internalizes and creates the membrane fusion among the viral subunit and the ACE2 receptors. This leads to the release of the viral RNA into the host cell and results into respiratory infection.Therefore, exploration of biologically active compounds to inhibit the SARS-CoV-2 spike protein into ACE2 receptor is the main priority (Figure 1).

Coronaviruses are present in a number of bat and bird species that are thought to serve as natural hosts. Molecular clock dating coronavirus analyzes suggest that the most recent common ancestor of these viruses was about 10,000 years ago. This relatively young age contrasts dramatically with the ancient evolutionary past of 
their supposed natural hosts, which started to diversify. It is found that the time for all coronaviruses common to the most recent ancestor is possibly much greater (millions of years) than the period previously inferred. In early $21^{\text {st }}$ Century, severe acute respiratory coronavirus syndrome (SARS-CoV) and Middle East respiratory coronavirus syndrome (MERS-CoV) are the two major and highly infectious and pathogenic bat borne coronaviruses posed severe threats to humans.

\section{Coronavirus cases in India}

India's coronavirus tally rose to 4.37 million with a single-day spike of 89,706 infections, while the death toll crossed the 73,890 mark with 1115 fresh fatalities, according to the Union Health Ministry data. The recoveries surged to 3.39 million pushing the recovery rate to 78 per cent. Meanwhile, Indian companies have asked the Russian Direct Investment Fund (RDIF) to provide the technical details of phase 1 and phase 2 clinical trials of Russia's coronavirus vaccine, the world's first registered vaccine against the infection. However, countries like India using dietary therapy and herbal medicines to prevent SARS-CoV-2 infections could be a complementary COVID-19 therapy, while drugs remain under development. Hence, the present review provides an insight into look at antiviral compounds from medicinal plants for the development of drugs for SARS-CoV-2 (Table 2).

Table 2: List of selected clinical trials for the amelioration of COVID-19 specific drugs and vaccines

\begin{tabular}{|c|c|c|c|c|}
\hline S.No. & Study & Drug & Status & Organizaion \\
\hline 1. & $\begin{array}{l}\text { Evalution of the efficacy and safety } \\
\text { of sarilumab in hospitalized patients } \\
\text { with COVID-19 }\end{array}$ & Sarilumab & Recruiting & Regeneron study site New York, United States \\
\hline 2. & $\begin{array}{l}\text { Study to evalute the safety and } \\
\text { antiviral activity of remdesivir } \\
\text { in participants with severe } \\
\text { coronavirus disease (COVID-19) }\end{array}$ & Remdesivir & Recruiting & $\begin{array}{l}\text { Hoag Memorial Hospital Presbyterian Newport } \\
\text { Beach, Californi, United States: Stanford } \\
\text { Hospital, Stanford, California, United States: } \\
\text { Providence Regional Medical Centre Everett, } \\
\text { Everett, Washington, United States }\end{array}$ \\
\hline 3. & Fingolimod in COVID-19 & $\begin{array}{l}\text { Fingolimod } \\
0.5 \mathrm{mg}\end{array}$ & Recruiting & Wan-Jin Chen Fuzhou, China \\
\hline 4. & $\begin{array}{l}\text { The clinical study of carrimycin on } \\
\text { treatment patients with COVID-19 }\end{array}$ & $\begin{array}{l}\text { Carrimycin } \\
\text { Lopinavir/ } \\
\text { ritonavir tablets } \\
\text { or arbidol or } \\
\text { chloroquine } \\
\text { phosphate }\end{array}$ & Not recruiting & - \\
\hline 5 & $\begin{array}{l}\text { Efficacy and safety of corticosteriods } \\
\text { in COVID-19 }\end{array}$ & Methylprednisolone & Recruiting & $\begin{array}{l}\text { Hubei Province Hospital of Integrated } \\
\text { Chinese and Western Medicine Wuhan, } \\
\text { Hubei, China Yichang First People s } \\
\text { Hospital Yuchang, Hubei, China Renmin } \\
\text { Hospital of Wuhan University Wuhan, China }\end{array}$ \\
\hline 6 & Mild/moderate 2019 nCoV remdesivir & Remdesivir & Recruiting & Jin Yin-tan Hospital. Wu Han, Hubei, China \\
\hline 7 & Adaptive COVID-19 treatment trial & Remdesivir & Recruiting & $\begin{array}{l}\text { National Institutes of Health Clinical Center, } \\
\text { National Institute of Allergy and Infectious } \\
\text { Disease Laboratory of Immunoregulation, } \\
\text { Clinical Research Section. Bethesda, Maryland, } \\
\text { United State University of Nebraska Medical } \\
\text { Center Infectious Diseases. Omaha, Nebraska, } \\
\text { United States. University of Texas Medical } \\
\text { Center Infectious Disease. Galveston, } \\
\text { Texas, United States Providence Sacred } \\
\text { Heart Medical Center Spokane, Washington, } \\
\text { United states }\end{array}$ \\
\hline
\end{tabular}




\begin{tabular}{|c|c|c|c|c|}
\hline 8 & Severe 2019-nCoV remdesivir RCT & Remdesivir & Recruiting & $\begin{array}{l}\text { Bin Cao } \\
\text { Beijing, Benijing, China }\end{array}$ \\
\hline 9 & $\begin{array}{l}\text { Nitric oxide gas inhalation for severe } \\
\text { acute respiratory syndrome in } \\
\text { COVID-19. }\end{array}$ & Nitric oxide gas & $\begin{array}{l}\text { Not yet } \\
\text { recruiting }\end{array}$ & - \\
\hline 10 & $\begin{array}{l}\text { Efficacy and safety of IFN- ' } 2 \text { ' in the } \\
\text { treatment of novel coronavirus } \\
\text { patients }\end{array}$ & $\begin{array}{l}\text { Recombinant human } \\
\text { interferons - '1' }\end{array}$ & $\begin{array}{l}\text { Not yet } \\
\text { recruiting }\end{array}$ & - \\
\hline 11 & $\begin{array}{l}\text { Evaluting and comparing the safety } \\
\text { and efficacy of ASCO9/ritonavir and } \\
\text { lopinavir/ ritonavir for novel } \\
\text { coronavirus infection }\end{array}$ & $\begin{array}{l}\text { ASCO9/ritonavir } \\
\text { group } \\
\text { Lopinavir/ritonavir } \\
\text { group }\end{array}$ & $\begin{array}{l}\text { Not yet } \\
\text { recruiting }\end{array}$ & \\
\hline 12 & $\begin{array}{l}\text { Safety and immunogenicity study of } \\
\text { 2019-nCoV vaccine (MRNA-1273) to } \\
\text { prevent SARS-CoV-2 infection }\end{array}$ & mRNA-1273 & $\begin{array}{l}\text { Not yet } \\
\text { recruiting }\end{array}$ & $\begin{array}{l}\text { Kaiser Permanente Washington Health Research Institute } \\
\text { Vaccines and Infectious Diseases }\end{array}$ \\
\hline 13 & $\begin{array}{l}\text { Glucocorticoid therapy for novel } \\
\text { coronavirus critically III patients } \\
\text { with severe acute respiratory failure }\end{array}$ & Methylprednisollone & Recruiting & $\begin{array}{l}\text { Medical ICU, Peking Union Medical College Hospital } \\
\text { Beijing, Beijing China }\end{array}$ \\
\hline 14 & $\begin{array}{l}\text { Lopinavir/ ritonavir, ribavirin and } \\
\text { IFN-beta combination for } \mathrm{nCoV}\end{array}$ & $\begin{array}{l}\text { Lopinavir/ritonavir } \\
\text { Ribavirin } \\
\text { Interferon beta-1B }\end{array}$ & Recruiting & $\begin{array}{l}\text { University of Hong Kong, Queen Marry Hospital Hong } \\
\text { Kong, Hong Kong }\end{array}$ \\
\hline 15 & $\begin{array}{l}\text { Efficacy of chloroquine and lopinavir } \\
\text { / ritonavir in mild/general novel } \\
\text { coronavirus (COVID-19) infections: } \\
\text { A prospective, open-label, multicenter } \\
\text { randomized controlled clinical study }\end{array}$ & $\begin{array}{l}\text { Chloroquine } \\
\text { Lopinavir / ritonavir }\end{array}$ & - & The Fifth Affiliated Hospital Sun Yat-Sen University \\
\hline 16 & $\begin{array}{l}\text { A study for the efficacy of } \\
\text { hydroxychloroquine for mild and } \\
\text { moderate COVID-19 infectious } \\
\text { diseases }\end{array}$ & Hydroxychloroquine & - & $\begin{array}{l}\text { The Second Affiliated Hospital of Chongqing Medical } \\
\text { University }\end{array}$ \\
\hline 17 & $\begin{array}{l}\text { A prospective, randomized, open- } \\
\text { label, parallel controlled trial for the } \\
\text { preventive effect of hydroxchlo- } \\
\text { roquine on medical personnel after } \\
\text { exposure to COVID-19 }\end{array}$ & Hydroxychloroquine & - & Renmin Hospital of Wuhan University \\
\hline 18 & $\begin{array}{l}\text { The efficacy and safety of carrimycin } \\
\text { treatment in patients with novel } \\
\text { coronavirus infectious disease } \\
\text { (COVID-19): multicenter } \\
\text { randomized, open-label controlled } \\
\text { trial }\end{array}$ & Carrimycin & - & Beijing Youan Hospital, Capital Medical University \\
\hline 19 & $\begin{array}{l}\text { A prospective clinical study for } \\
\text { recombinant human interferon alpha } \\
\text { infection in highly exposed medical } \\
\text { staffs }\end{array}$ & $\begin{array}{l}\text { Recombinant } \\
\text { humaninterferon } \\
\text { alpha } 1 \mathrm{~b}\end{array}$ & - & Chinese PLA General Hospital \\
\hline 20 & $\begin{array}{l}\text { A pilot study of sildenafil in } \\
\text { COVID-19 }\end{array}$ & Sildenafil citrate & Recruiting & $\begin{array}{l}\text { Department and Institute of Infectious Disease, Wuhan } \\
\text { Hubei, China }\end{array}$ \\
\hline 21 & $\begin{array}{l}\text { Comparison of lopinavir/ ritonavir or } \\
\text { hydroxychloroquine in patients with } \\
\text { mild coronavirus disease (COVID-19) }\end{array}$ & $\begin{array}{l}\text { Lopinavir/ ritonavir } \\
\text { hydroxychloroquine } \\
\text { sulfate }\end{array}$ & Recruiting & $\begin{array}{l}\text { Asan Medical Center, University of Ulsan College of } \\
\text { Medicine, Seoul, Korea, Republic of Korea }\end{array}$ \\
\hline
\end{tabular}




\begin{tabular}{|c|c|c|c|c|}
\hline 22 & $\begin{array}{l}\text { The efficacy and safety of thalidomide } \\
\text { combined with low-dose hormones in the } \\
\text { treatment of severe COVID-19 }\end{array}$ & Thalidomide & $\begin{array}{l}\text { Not yet } \\
\text { recruiting }\end{array}$ & - \\
\hline 23 & $\begin{array}{l}\text { Various combination of protease } \\
\text { inhibitors, oseltamivir, favipiravir, and } \\
\text { chloroquine for treatment of COVID-19: } \\
\text { A randomized control trial. }\end{array}$ & Oral & $\begin{array}{l}\text { Not yet } \\
\text { recruiting }\end{array}$ & Subsai Kongsaengdao, Bangkok, Thailand \\
\hline 24 & $\begin{array}{l}\text { Chloroquine prevention of coronavirus } \\
\text { diseas (COVID-19) in the healthcare } \\
\text { setting }\end{array}$ & Chloroquine & $\begin{array}{l}\text { Not yet } \\
\text { recruiting }\end{array}$ & - \\
\hline 25 & $\begin{array}{l}\text { Favipiravir combined with tocilizumab in } \\
\text { the treatment of coronavirus disease } 2019\end{array}$ & $\begin{array}{l}\text { Favipiravir combined } \\
\text { with tocilizumab }\end{array}$ & Recruiting & $\begin{array}{l}\text { Anhui Medical University Affiliated First } \\
\text { Hospital, Hefei, Anhui, China } \\
\text { Guiqjang Wang, Beijing, Beijing, China } \\
\text { Peking University First Hospital, Beijing, } \\
\text { China }\end{array}$ \\
\hline 26 & $\begin{array}{l}\text { Trial treatment for COVID-19 in } \\
\text { hospitalized adults }\end{array}$ & $\begin{array}{l}\text { Remdesivir } \\
\text { Lopinavir/ ritonavir } \\
\text { interferon beta-1A }\end{array}$ & $\begin{array}{l}\text { Not yet } \\
\text { recruiting }\end{array}$ & - \\
\hline 27 & $\begin{array}{l}\text { Randomized controlled trial of losartan for } \\
\text { patients with COVID-19 losartan } \\
\text { requiring hospitalization }\end{array}$ & Losartan & $\begin{array}{l}\text { Not yet } \\
\text { recruiting }\end{array}$ & $\begin{array}{l}\text { Hennepin Country Medical Center, } \\
\text { Minneapolis, Minnesota, United States } \\
\text { M Health Fairview University of Minnesota, } \\
\text { Medical Center, Minneapolis, Minnesota, } \\
\text { United States } \\
\text { University of Minnesota Medical Center, } \\
\text { Minneapolis, Minnesota, United States }\end{array}$ \\
\hline 28 & $\begin{array}{l}\text { Evaluation of ganovo (danoprevir) } \\
\text { combined with ritonavir in the treatment } \\
\text { of novel coronavirus infection }\end{array}$ & $\begin{array}{l}\text { Ganovo with ritonavir } \\
+/ \text { - Interferon }\end{array}$ & Recruiting & $\begin{array}{l}\text { The Ninth Hospital of Nanchang } \\
\text { Nanchang, Jiangxi, China }\end{array}$ \\
\hline 29 & $\begin{array}{l}\text { Eculizumab (soliris) in COVID-19 } \\
\text { infected patients }\end{array}$ & Eculizumab & Initiated & - \\
\hline 30 & $\begin{array}{l}\text { Expanded access remdesivir (RDV; GS- } \\
5734^{\mathrm{TM}}\end{array}$ & Remdesivir & Initiated & - \\
\hline 31 & $\begin{array}{l}\text { Norwegian coronavirus disease } 2019 \\
\text { study }\end{array}$ & $\begin{array}{l}\text { Hydroxychloroquine } \\
\text { sulfate }\end{array}$ & $\begin{array}{l}\text { Not yet } \\
\text { recruiting }\end{array}$ & - \\
\hline 32 & $\begin{array}{l}\text { Post-exposure prophylaxis for SARS- } \\
\text { coronavirus-2 }\end{array}$ & Hydroxychloroquine & Recruiting & $\begin{array}{l}\text { University of Minnesota Medical Center, } \\
\text { Minneapolis, Minnesota, United States }\end{array}$ \\
\hline 33 & $\begin{array}{l}\text { The efficacy and the safety of pirfenidone } \\
\text { capsules in the treatment of severe new } \\
\text { coronavirus pneumonia (COVID-19) }\end{array}$ & Pirfenidone & - & $\begin{array}{l}\text { Third Xizngya Hospital of Central South } \\
\text { University }\end{array}$ \\
\hline
\end{tabular}

Source: Vellingiri et al. (2020) 
Many researchers have determined the inhibitory ability of various active compounds from natural resources. Compounds such as asiatic acid, andrographolide, apigenin, brazilein, brazilin, catechin, curcumin, gingerol, hesperidin, hesperetin, kaemferol, luteolin, myricetin, naringenin and quercetin against the target protein of COVID-19, particularly ACE2, TMPRSS2, RdRp, 3CLpro and PLpro through molecular docking studies by evaluating the binding energy between the active compound and the target proteins are well known (Laksmiani et al., 2020). Laksmiani et al. (2020) reported few active chemical compounds in medicinal plants showed excellent affinity towards target protein proved that they can be used as antivirals against SARS-CoV-2. The active compounds from Caesalpinia sappan L. such as brazilein and brazilin had an excellent affinity towards ACE2. Hesperidin from Citrus sp. to TMPRSS2 with most negative value of docking score and lower binding energy value than drugs such as arbidol, chloroquine, camostatmesylate, remdesivir and lopinavir that used as inhibitor agent to COVID-19 (Laksmiani et al., 2020). Hence, the aforementioned medicinal plants could be a potential source of antivirals to develop drugs against SARS-CoV-2 through inhibiting ACE2, TMPRSS2, RdRp and protease (3CLpro and PLpro) that interfered the process of virus infection which causing pneumonia (Laksmiani et al., 2020). Glycyrrhizin isolated from Glycyrrhiza glabra roots was found effective in preventing the SARS-CoV replication (Cinatl et al., 2003a); myricetin from Myrica rubra, scutellarein from Scutettaria baicalensis and Asplenium belangeri are known to inhibit the ATPase activity of SARS-CoV helicase nsP13 (Yu et al., 2020); amentoflavone, quercetin, luteolin and apigenin from Torreya nucifera (Ryu et al.,
2010) and emodin, sinigrin and hesperetin extracted from Isatis indigotica (Lin et al., 2005) have inhibit 3CLpro function. Water extract of Houttuynia cordata has antiviral activity against SARS$\mathrm{CoV}$ due to its inhibitory effect on 3C-like protease (3CLpro) and RNA-dependent RNA polymerase (RdRp) of the virus; lycorine from Lycoris radiate (Li et al., 2005); 13 mannose-binding lectins identified to possess a robust anti-coronaviral activity (Keyaerts et al., 2007). Another lectin, agglutinin isolated from Galanthus nivalis, was effective against FCoV when administered in combination with a synthetic drug nelfinavir (Hsieh et al., 2010). Recently, resveratrol (trans-3, 5, 42-trihydroxystilbene) a natural stilbene derivative present in abundance in Vitis vinifera, Polygonum cuspidatum, and as Vaccinium macrocarpon showed inhibition of MERS-CoV infection (Lin et al., 2017).

Sivaraman and Pradeep (2020) and Vellingiri et al. (2020) had underlined the positive side of this plant-based concoction that keeps the infection levels at bay. Identification of the antiviral mechanisms from these natural agents has helped to understand how and where they interact with the viral life cycle, such as viral entry, replication, assembly, and release, as well as on the targeting of virus-host-specific interactions. It has been shown that natural plants (Table 3) contain antiviral activities to coronaviruses (McCutcheon et al., 1995) and the mechanism of action is to inhibit viral replication (Vlietinck and Vanden Berghe, 1991; Jassim and Naji, 2003). The Table 3 provides ethnobotanical details with respect to SARS - severe acute respiratory syndrome, MERS-Middle East respiratory syncytial virus, ARVI-Acute respiratory viral infections.

Table 3: List of ethnobotanicals and their mode of action against $\mathrm{CoV}$

\begin{tabular}{|c|c|c|c|c|c|}
\hline S. No. & Plant source & Mechanism of action & Target & Virus & References \\
\hline 1 & Acacia nilotica & Inhibition & - & HIV-PR & Mishra et al., 2014 \\
\hline 2 & Allium sativum & $\begin{array}{l}\text { Proteolytic and hemagglutinating } \\
\text { activity and viral replication }\end{array}$ & - & SARS & Keyaerts et al., 2004 \\
\hline 3 & Andrographis paniculata & Suppression & $\begin{array}{l}\text { NLRP3, } \\
\text { Capase-1, } \\
\text { and IL-1] }\end{array}$ & $\begin{array}{l}\text { SARS-COV } \\
\text { and likely } \\
\text { SARS-COV-2 }\end{array}$ & Liu et al., 2020a, 2020b \\
\hline 4 & Boerhaavia diffusa & Inhibition & ACE & - & $\begin{array}{l}\text { Prathapan et al., 2013; } \\
\text { Khan and Kumar, } 2019\end{array}$ \\
\hline 5 & Clerodendrum inerme & Inactivation & Ribosome & SARS-CoV-2 & Olivierir et al., 1996 \\
\hline 6 & Clitoria ternatea & Metalloproteinase inhibitor & ADAM17 & - & Maity et al., 2012 \\
\hline 7 & Coriandrum sativum & Inhibition & ACE & - & Pandey et al., 2011 \\
\hline 8 & $\begin{array}{l}\text { Cynara scolymus } \\
\text { Cassia occidentalis } \\
\text { Cascinium fernestratum }\end{array}$ & Inhibition & $\mathrm{ACE}$ & - & $\begin{array}{l}\text { Prathapan et al., 2013; } \\
\text { Khan and Kumar, } 2019\end{array}$ \\
\hline 9 & Embelia ribes & Inhibition & ACE & - & $\begin{array}{l}\text { Prathapan et al., 2013; } \\
\text { Khan and Kumar, } 2019\end{array}$ \\
\hline 10 & Eugenia jambolana & Inhibition & Protease & - & Otake et al., 1995 \\
\hline 11 & Euphorbia granulata & Inhibition & - & HIV-1PR & Mishra et al., 2014 \\
\hline 12 & Glycyrrhiza glabra & $\begin{array}{l}\text { Inhibition of viral replication: } \\
\text { Modulaton of membrane fluidity }\end{array}$ & - & SARS; HIV-1 & $\begin{array}{l}\text { Akamatsu et al., 1991; } \\
\text { Cinatl et al., 2003a; } \\
\text { Fiore et al., } 2008\end{array}$ \\
\hline 13 & Gymnema sylvestre & Inhibition of viral DNA synthesis & - & - & $\begin{array}{l}\text { Vimalanathan et al., } 2009 \text {; } \\
\text { Arun et al., } 2014\end{array}$ \\
\hline
\end{tabular}




\begin{tabular}{|c|c|c|c|c|c|}
\hline 14 & Hyoscyamus niger & Inhibition and Bronchodilator & $\mathrm{Ca} 2+$ & - & Gilani et al., 2008 \\
\hline 15 & Ocimum lilimandscharicum & Inhibition & - & HIV-1 & $\begin{array}{l}\text { Thayilseema and } \\
\text { Thyagarajan, } 2016\end{array}$ \\
\hline 16 & Ocimum sanctum & Inhibition & - & HIV-1 & Rege and Chewdhary, 2014 \\
\hline 17 & Punica granatum & Inhibition & ACE & - & $\begin{array}{l}\text { Prathapan et al., 2013; } \\
\text { Khan and Kumar, } 2019\end{array}$ \\
\hline 18 & Salacia oblonga & Suppression & $\begin{array}{l}\text { Angio } \\
\text { tensin II, } \\
\text { ATI Signal }\end{array}$ & - & He et al., 2011 \\
\hline 19 & Sambucus ebulus & Inhibition & - & $\begin{array}{l}\text { Enveloped } \\
\text { virus }\end{array}$ & Ganjhu et al., 2015 \\
\hline 20 & Solanum nigrum & - & - & HIV-1 & Yu, 2004 \\
\hline 21 & Sphaeranthus indicus & Inhibition & - & $\begin{array}{l}\text { Mouse } \\
\text { coronavirus } \\
\text { and } \\
\text { Herpesvirus }\end{array}$ & $\begin{array}{l}\text { Galani et al., } 2010 \\
\text { Tiwari and Khosa, 2009; } \\
\text { Vimalanathan et al., } 2009\end{array}$ \\
\hline 22 & Strobilanthes callosa & Blocking & - & HCoV-NL63 & Tsai et al., 2020 \\
\hline 23 & Strobilanthes cusia & Blocking & - & HCoV-NL63 & Tsai et al., 2020 \\
\hline 24 & Vitex negundo & Inhibition & - & HIV-1 & Nair, 2012 \\
\hline 25 & Vitex trifolia & Reduction & - & SARS-CoV & Liou et al., 2018 \\
\hline
\end{tabular}

Note: HIV-IPR: Human Influenza Virus -1 Protease; SARS; Severe Acute Respiratory Syndrome; SARS-CoV: Severe Acute Respiratory Syndrome-Coronavirus; ACE-Angiotensin converting enzyme; HIV-1; Human Influenza Virus-1; gp120; Envelope Glycoprotein 120; CD4; Cluster of Differentiation; HCoV-NL63; Human coronavirus NI62; RNA ; Ribonucleic acid; MHV-A59; Mouse Hepatitis Virus-A59; Ca2+: Calcium ion; NLRP3: NLR Family Pyrin Domain Containing 3; ATIAngiotensin 1; HCoV-NL63: Human Coronavirus-NL63.

Table 4: Bioproducts against $\mathrm{CoV}$

\begin{tabular}{|c|c|c|c|c|c|}
\hline $\begin{array}{l}\text { Extracts or } \\
\text { preparations }\end{array}$ & Test system & $\begin{array}{l}\text { Test dose/ } \\
\text { concentration }\end{array}$ & $\begin{array}{l}\text { Proposed } \\
\text { mechanism }\end{array}$ & $\begin{array}{l}\text { IC50 or } \\
\text { EC50 value }\end{array}$ & References \\
\hline Lycorisradiata & SARS-CoV & $10^{-1}-10^{-4} \mathrm{mg} / \mathrm{ml}$ & Undefined & $2.4 \pm 0.2 \mu \mathrm{g} / \mathrm{ml}$ & Li et al., 2005 \\
\hline Artemisia lingua & SARS-CoV & $10^{-1}-10^{-4} \mathrm{mg} / \mathrm{ml}$ & Undefined & $34.5 \pm 2.6 \mu \mathrm{g} / \mathrm{ml}$ & Li et al., 2005 \\
\hline Pyrrosia lingua & SARS-CoV & $10^{-1}-10^{-4} \mathrm{mg} / \mathrm{ml}$ & Undefined & $43.2 \pm 14.1 \mu \mathrm{g} / \mathrm{ml}$ & Li et al., 2005 \\
\hline Lindera aggregate & SARS-CoV & $10^{-1}-10^{-4} \mathrm{mg} / \mathrm{ml}$ & Undefined & $88.2 \pm 7.7 \mu \mathrm{g} / \mathrm{ml}$ & Li et al., 2005 \\
\hline Isatis indigotica & SARS-CoV & $1-500 \mu \mathrm{g} / \mathrm{ml}$ & $3 \mathrm{CL}$ protease inhibition & - & Li et al., 2005 \\
\hline $\begin{array}{l}\text { Extract of Rheum officinale } \\
\text { and Polygonumm ultiflorum }\end{array}$ & SARS-CoV & $0-100 \mu \mathrm{g} / \mathrm{ml}$ & $\begin{array}{l}\text { Inhibits the interaction } \\
\text { of SARS-CoV S protein } \\
\text { and ACE2. }\end{array}$ & 1 to $10 \mu \mathrm{g} / \mathrm{ml}$ & $\begin{array}{l}\text { Ho, Wu, Chen, } \\
\text { Li, and } \\
\text { Hsiang, } 2007\end{array}$ \\
\hline Houttuynia cordata aq. Extract & SARS-CoV & $0-400 \mu \mathrm{g} / \mathrm{ml}$ & $\begin{array}{l}\text { 3CL protease and viral } \\
\text { polymerase inhibition }\end{array}$ & - & Lau et al., 2008 \\
\hline $\begin{array}{l}\text { Herbal extracts (Gentiana } \\
\text { scabra, Dioscorea batatas, } \\
\text { Cassia tora, Taxillus chinensis, } \\
\text { Cibotium barometz) }\end{array}$ & SARS-CoV & $25-200 \mu \mathrm{g} / \mathrm{ml}$ & $3 \mathrm{CL}$ protease inhibition & $\begin{array}{l}39 \mu \mathrm{g} / \mathrm{mL} \text { and } \\
44 \mu \mathrm{g} / \mathrm{mL} \text { (Two } \\
\text { extracts of Cibo- } \\
\text { tiumbarometz) }\end{array}$ & Wen et al., 2011 \\
\hline $\begin{array}{l}\text { Anthemis hyaline, Nigella } \\
\text { sativa and Citrus sinensis } \\
\text { extracts }\end{array}$ & $\begin{array}{l}\text { Coronavirus infected } \\
\text { HeLa-epithelial } \\
\text { carcinoembryonic } \\
\text { antigen-related } \\
\text { cell adhesion } \\
\text { molecule Ia cells } \\
\text { inoculated with } \\
\text { MHV-A59 (Mouse } \\
\text { hepatitis virus-A59) }\end{array}$ & $\begin{array}{l}1 / 50 \text { and } 1 / 100 \\
\text { dilution of } \\
\text { ethanolic } \\
\text { extract } \\
(100 \mathrm{~g} / 200 \mathrm{ml})\end{array}$ & $\begin{array}{l}\text { Increased IL-8 level, } \\
\text { Significantly changed } \\
\text { the expression of } \\
\text { TRPA1,TRPC4, } \\
\text { TRPM^, TRPM7, } \\
\text { TRPM8 and TRPV4 } \\
\text { genes }\end{array}$ & - & $\begin{array}{l}\text { Ulasli et al., } \\
2014\end{array}$ \\
\hline
\end{tabular}




\section{Natural products inhibiting virulence effect of $\mathrm{CoV}$ infection}

Nature provides a vast library of chemicals to explore and develop drugs for treatment of various ailments including viral diseases (Denaro et al., 2019). Natural products and their derivatives are used in folk medicine will have always played a crucial role in drug development process against various diseases, which resulted in screening of such agents to combat emergent mutants of coronavirus (Ganjhu et al., 2015). There is a vast scope for herbal medicines in the view of nutraceuticals market (Williamson et al., 2020). Interestingly, the acceptability and, therefore, research on plant based drugs are growing on a daily basis. Some natural products have been found to exhibit their antiviral activity through the inhibition of viral replication (Moghadamtousi et al., 2015; Oliveira et al., 2017). Apart from plant derived compounds (Jardim et al., 2018), several marine natural products (Wang et al., 2014) as well as biotechnologically produced compounds (Neumann and Neumann Staubitz, 2010) are also reported for their antiviral properties against different viruses. Along this line, Nigella sativa demonstrated its inhibitory activity against hepatitis $\mathrm{C}$ virus (Oyero et al., 2016). General mechanism for antiviral activity of most of the natural products is inhibition of viral replication and some natural products (e.g., lycorine, homoharringtonine, silvestrol, ouabin, tylophorine and 7 methoxycryptopleurine) have interacted with important virulent viral proteins (Table 4).The natural compounds, procyanidin $\mathrm{A} 2$, procyanidin $\mathrm{B} 1$, and cinnamtannin B1, isolated from Cinnamomi cortex inhibited SARS-CoV infection at $0-500 \mu \mathrm{M}$ (Zhuang et al., 2009). On the other hand, tetra $O$ galloyl beta $\mathrm{D}$ glucose, luteolin, and tetra $O$ galloyl beta $\mathrm{D}$ glucose blocked the host cell entry of SARS-CoV at $0-10^{\prime 3} \mathrm{~mol} / \mathrm{l}$ (Yi et al., 2004). In another study, bavachinin, neobavaisoflavone, isobavachalcone, 4' $O$ methylbavachalcone, psoralidin, and corylifol isolated from Psoralea corylifolia inhibited papain like protease of SARS-CoV (Kim et al., 2014). Interestingly, psoralidin exhibited a strong protease inhibitory effect on SARS-CoV with an $\mathrm{IC}_{50}$ value $4.2 \mu \mathrm{M}$, whereas emodin, rhein, and chrysin inhibited interaction of SARS-CoV (S) protein and ACE2 at 0-400 $\mu \mathrm{M}$ (Ho et al., 2007). Listed in Table 4 are crude extracts and Table 5 are isolated compounds that display activity against $\mathrm{CoV}$. In addition, a good number of natural products with anti coronavirus activity are the major constituents of some common dietary supplements, which can be exploited to improve the immunity of the general population in certain epidemics. Lin et al. (2014) reported a good number of herbal medicines have shown potential antiviral activity.

Table 5: Efficacy of secondary metabolites and their derivatives against $\mathrm{CoV}$ infection

\begin{tabular}{|c|c|c|c|c|c|}
\hline $\begin{array}{l}\text { Compounds } \\
\text { (Biological } \\
\text { source) }\end{array}$ & Test system mechanism & $\begin{array}{l}\text { Dose } \\
\text { concentration }\end{array}$ & Proposed & $\begin{array}{l}\mathrm{IC}_{50} \text { or } \mathrm{EC}_{50} \\
\text { value }\end{array}$ & References \\
\hline $\begin{array}{l}\text { Aloe emodin } \\
\text { (Isatis indigotica) }\end{array}$ & SARS-CoV & $1-100 \mu \mathrm{g} / \mathrm{ml}$ & $3 \mathrm{CL}$ protease inhibition & $8.3 \mu \mathrm{M}$ & Lin et al., 2005 \\
\hline $\begin{array}{l}\text { Amentoflavone } \\
\text { (Torreya nucifera) }\end{array}$ & SARS-CoV & $1-1000 \mu \mathrm{M}$ & $3 \mathrm{CL}$ protease inhibition & $8.3 \mu \mathrm{M}$ & Ryu et al., 2010 \\
\hline $\begin{array}{l}\text { Apigenin } \\
\text { (Torreya nucifera) }\end{array}$ & SARS-CoV & $1-1000 \mu \mathrm{M}$ & $3 \mathrm{CL}$ protease inhibition & $280.8 \mu \mathrm{M}$ & Ryu et al., 2010 \\
\hline $\begin{array}{l}\text { Bavachinin } \\
\text { (Psoralea corylifolia) }\end{array}$ & SARS-CoV & $1-150 \mu \mathrm{M}$ & $\begin{array}{l}\text { Inhibitors of papain like } \\
\text { protease (PLpro). }\end{array}$ & $\begin{array}{l}38.4 \pm 2.4 \\
\mu \mathrm{M}\end{array}$ & Kin et al., 2014 \\
\hline Berbamine & HCoV-NL63 & $0-20 \mu \mathrm{M}$ & Undefined & $1.48 \mu \mathrm{M}$ & Kin et al., 2019 \\
\hline $\begin{array}{l}\text { Beta-sitosterol } \\
\text { (Isatis indigotica) }\end{array}$ & SARS-CoV & $1-100 \mu \mathrm{g} / \mathrm{ml}$ & $3 \mathrm{CL}$ protease inhibition & $1210 \mu \mathrm{M}$ & Lin et al., 2005 \\
\hline Betulonic acid & SARS-CoV & $0-10 \mu \mathrm{M}$ & Inhibition of replication & $0.63 \mu \mathrm{M}$ & Wen et al., 2007 \\
\hline Betulonic acid & SARS-CoV & $8-80 \mu \mathrm{M}$ & $3 \mathrm{CL}$ protease inhibition & $10 \mu \mathrm{M}$ & Wen et al., 2007 \\
\hline Betulonic acid & SARS-CoV & $8-80 \mu \mathrm{M}$ & 3CL protease inhibition & $>100 \mu \mathrm{M}$ & Wen et al., 2007 \\
\hline $\begin{array}{l}\text { Broussochalcone A } \\
\text { (Broussonetia } \\
\text { papyrifera) }\end{array}$ & $\begin{array}{l}\text { 3-chymotrypsin -like and } \\
\text { papain -like coronavirus } \\
\text { cysteine proteases }\end{array}$ & $0-200 \mu \mathrm{M}$ & Protease inhibition & - & Park et al., 2017 \\
\hline $\begin{array}{l}\text { (-) Catechingallate and } \\
\text { (-) Gallocatechingallate }\end{array}$ & SARS-CoV & $0.001-1 \mu \mathrm{g} / \mathrm{ml}$ & $\begin{array}{l}\text { Inhibition of } \\
\text { nanoparticle-based } \\
\text { RNA oligonucleotide }\end{array}$ & - & Roh, 2012 \\
\hline
\end{tabular}




\begin{tabular}{|c|c|c|c|c|c|}
\hline Cepharanthine & SARS-CoV & $0.5-10 \mu \mathrm{g} / \mathrm{ml}$ & Protease inhibition & $9.5 \mu \mathrm{g} / \mathrm{ml}$ & Zhang et al., 2005 \\
\hline Cepharanthine & $\begin{array}{l}\text { HCoV-OC43-infected } \\
\text { MRC-5 human lung cells }\end{array}$ & $2-20 \mu \mathrm{M}$ & Undefined & $\begin{array}{l}0.83 \pm 0.07 \\
\mu \mathrm{M}\end{array}$ & Kim et al., 2019 \\
\hline $\begin{array}{l}\text { Cinanserin ( } 1 \mathrm{dpi}) \\
\text { (Houttuynia cordata) }\end{array}$ & Murine $\mathrm{CoV}$ & $500-15.63 \mu \mathrm{g} / \mathrm{ml}$ & Undefined & $31.25 \mu \mathrm{g} / \mathrm{ml}$ & Chiow et al., 2016 \\
\hline $\begin{array}{l}\text { Cinanserin ( } 2 \mathrm{dpi}) \\
\text { (Houttuynia cordata) }\end{array}$ & Murine $\mathrm{CoV}$ & $15.63-500 \mu \mathrm{g} / \mathrm{ml}$ & Undefined & $62.50 \mu \mathrm{g} / \mathrm{ml}$ & Chiow et al., 2016 \\
\hline $\begin{array}{l}\text { Cinnamtannin } \\
\text { B1 (Cinnamomi cortex) }\end{array}$ & SARS-CoV & $0-500 \mu \mathrm{M}$ & $\begin{array}{l}\text { Inhibition of } \\
\text { pseudovirus infection }\end{array}$ & $\begin{array}{l}32.9 \pm 3.9 \\
\mu \mathrm{M}\end{array}$ & $\begin{array}{l}\text { Zhuang et al., } \\
2009\end{array}$ \\
\hline $\begin{array}{l}\text { Chrysin (5,7-dihydroxy- } \\
\text { flavone) }\end{array}$ & SARS-CoV & $0-400 \mu \mathrm{M}$ & $\begin{array}{l}\text { Inhibited interaction } \\
\text { of SARS-CoV (S) protein } \\
\text { and ACE2 }\end{array}$ & - & Ho et al., 2007 \\
\hline Concanavalin A & - & - & $\begin{array}{l}\text { Lose the haemaagglutina- } \\
\text { tion properties of the } \\
\text { virus envelope and acause } \\
\text { datransient interference } \\
\text { with infectivity }\end{array}$ & - & $\begin{array}{l}\text { Greig and } \\
\text { Bouillant, } 1977\end{array}$ \\
\hline $\begin{array}{l}\text { Corylifol (Psoralea } \\
\text { corylifolia) }\end{array}$ & SARS-CoV & $1-150 \mu \mathrm{M}$ & $\begin{array}{l}\text { Inhibitors of papain } \\
\text { like protease (PLpro) }\end{array}$ & $\begin{array}{l}32.3 \pm 3.2 \\
\mu \mathrm{M}\end{array}$ & Kim et al., 2014 \\
\hline Curcumin & SARS-CoV & $8-80 \mu \mathrm{M}$ & $\begin{array}{l}\text { Inhibition of } 3 \mathrm{CL} \\
\text { protease }\end{array}$ & $40 \mu \mathrm{M}$ & Wen et al., 2007 \\
\hline Dieckol (Ecklonia cava) & $\begin{array}{l}\text { Porcine epidemic diarrhea } \\
\mathrm{CoV}\end{array}$ & $1-200 \mu \mathrm{M}$ & $\begin{array}{l}\text { Inhibition of viral } \\
\text { replication }\end{array}$ & $\begin{array}{l}14.6 \pm 1.3 \\
\mu \mathrm{M}\end{array}$ & $\begin{array}{l}\text { Kwon et al., } \\
2013\end{array}$ \\
\hline $\begin{array}{l}\text { Diplacone (Paulownia } \\
\text { tomentosa) }\end{array}$ & SARS-CoV & $0-100 \mu \mathrm{M}$ & $\begin{array}{l}\text { Inhibition of papain } \\
\text { like protease }\end{array}$ & $\begin{array}{l}10.4 \pm 0.16 \\
\mu \mathrm{M}\end{array}$ & Chow et al., 2013 \\
\hline $\begin{array}{l}\text { 3ß,12-diacetoxyabieta- } \\
6,8,11,13 \text {-tetraene }\end{array}$ & SARS-CoV & $0-10 \mu \mathrm{M}$ & Inhibition of replication & $1.57 \mu \mathrm{M}$ & Wen et al., 2007 \\
\hline $\begin{array}{l}\text { 1-(4,5-Dihydroxy-3- } \\
\text { hydroxymethylcy- } \\
\text { clopente-2-enyl)- } 1 \mathrm{H}- \\
1,2,4 \text {-triazole- } 3 \text { - } \\
\text { carboxylic acid amide }\end{array}$ & SARS-CoV & - & Undefined & $21 \mu \mathrm{M}$ & Cho et al., 2006 \\
\hline $\begin{array}{l}\text { 1-(4,5-Dihydroxy-3- } \\
\text { hydroxymethylcy- } \\
\text { clopente-2-enyl)-1H- } \\
1,2,4 \text {-triazole-3- } \\
\text { carboxylic acid amide }\end{array}$ & SARS-CoV & - & Undefined & $47 \mu \mathrm{M}$ & Cho et al., 2006 \\
\hline Eckol (Ecklonia cava) & $\begin{array}{l}\text { Porcine epidemic } \\
\text { diarrhea } \mathrm{CoV}\end{array}$ & $1-200 \mu \mathrm{M}$ & $\begin{array}{l}\text { Blockage of the binding } \\
\text { of virus to cells }\end{array}$ & $\begin{array}{l}22.5 \pm 2.2 \\
\mu \mathrm{M}\end{array}$ & $\begin{array}{l}\text { Cho et al., } \\
2013\end{array}$ \\
\hline Emetine & $\begin{array}{l}\mathrm{HCoV}-\mathrm{OC} 43, \mathrm{HCoV}- \\
\text { NL63,MERS-CoV and } \\
\text { MHV-A59 }\end{array}$ & $0-5 \mu \mathrm{M}$ & $\begin{array}{l}\text { Inhibited RNA,DNA } \\
\text { and Protein synthesis }\end{array}$ & $\begin{array}{l}0.30,1.43 \\
0.34 \text { and } \\
0.12 \mu \mathrm{M}\end{array}$ & Shen et al., 2019 \\
\hline $\begin{array}{l}\text { Emodin ( } 1,3,8 \text {-trihyd- } \\
\text { roxy-6-methylanthra- } \\
\text { quinone) }\end{array}$ & SARS-CoV & $0-400 \mu \mathrm{M}$ & $\begin{array}{l}\text { Inhibited interaction of } \\
\text { SARS-CoV }(S) \text { protein } \\
\text { and ACE2 }\end{array}$ & $200 \mu \mathrm{M}$ & Ho et al., 2007 \\
\hline Fangchinoline & $\begin{array}{l}\text { HCoV-OC43-infected } \\
\text { MRC-5 human lung cells }\end{array}$ & $2-20 \mu \mathrm{M}$ & Undefined & $\begin{array}{l}1.01 \pm 0.07 \\
\mu \mathrm{M}\end{array}$ & Kim et al., 2019 \\
\hline Ferruginol & SARS-CoV & $0-10 \mu \mathrm{M}$ & Inhibition of replication & $1.39 \mu \mathrm{M}$ & Wen et al., 2007 \\
\hline $\begin{array}{l}\text { 6-geranyl-4',5-7-trihy- } \\
\text { droxy-3',5'-dimethoxy- } \\
\text { flavanone (Paulownia } \\
\text { tomentosa) }\end{array}$ & SARS-CoV & $0-10 \mu \mathrm{M}$ & Inhibition of replication & $\begin{array}{l}13.9 \pm 0.18 \\
\mu \mathrm{M}\end{array}$ & Cho et al., 2013 \\
\hline $\begin{array}{l}\text { Halituna (Halimeda } \\
\text { tuna) }\end{array}$ & Murine coronavirus A59 & - & Undefined & - & $\begin{array}{l}\text { Koehn et al., } \\
1991\end{array}$ \\
\hline
\end{tabular}




\begin{tabular}{|c|c|c|c|c|c|}
\hline $\begin{array}{l}\text { Hesperetin (Isatis } \\
\text { indigotica) }\end{array}$ & SARS-CoV & $1-100 \mu \mathrm{g} / \mathrm{ml}$ & $3 \mathrm{CL}$ protease inhibition & $365 \mu \mathrm{M}$ & Lin et al., 2005 \\
\hline Hexachlorophene & Murine CoV (MHV-2aFLS) & $0-10 \mu \mathrm{M}$ & Undefined & $1.2 \mu \mathrm{M}$ & Cao et al., 2015 \\
\hline Hinokinin & SARS-CoV & $8-80 \mu \mathrm{M}$ & $3 \mathrm{CL}$ protease inhibition & $>100 \mu \mathrm{M}$ & Wen et al., 2007 \\
\hline Homoharringtonine & Murine CoV (MHV-2aFLS) & $0-70 \mathrm{nM}$ & Undefined & $12 \mathrm{nM}$ & Cao et al., 2015 \\
\hline $\begin{array}{l}\text { 4-Hydroxyisolon- } \\
\text { chocarpin } \\
\text { (Broussonetia } \\
\text { papyrifera) }\end{array}$ & $\begin{array}{l}3 \text {-chymotrypsin-like and } \\
\text { papain-like coronavirus } \\
\text { cysteine proteases }\end{array}$ & $0-200 \mu \mathrm{M}$ & Protease inhibition & - & Park et al., 2017 \\
\hline $\begin{array}{l}\text { Hygromycin B } \\
\text { (Streptomyces } \\
\text { hygroscopicus) }\end{array}$ & $\begin{array}{l}\text { Mouse hepatitis virus } \\
\text { (MHV-A59) }\end{array}$ & $0-1 \mu \mathrm{M} / \mathrm{kg}$ & $\begin{array}{l}\text { Reduced virus } \\
\text { replication and } \\
\text { necrotic liver foci }\end{array}$ & - & $\begin{array}{l}\text { Macintyre } \text { et al., } \\
1991\end{array}$ \\
\hline $\begin{array}{l}\text { 8B-hydroxyabieta } \\
-9(11), 13 \text {-dien-12-one }\end{array}$ & SARS-CoV & $0-10 \mu \mathrm{M}$ & Inhibition of replication & $1.47 \mu \mathrm{M}$ & Wen et al., 2007 \\
\hline Indigo (Isatis indigotica) & SARS-CoV & $1-100 \mu \mathrm{g} / \mathrm{ml}$ & $3 C L$ protease inhibition & $752 \mu \mathrm{M}$ & Lin et al., 2005 \\
\hline
\end{tabular}

\section{Conclusion}

COVID-19 a newly emerged upper respiratory tract viral respiratory disease caused by the coronavirus, Severe acute respiratory syndrome coronavirus 2(SARS-CoV-2) is identified from China, in December 2019, spreads rapidly across worldwide. A novel coronavirus disease (COVID-19) is zoonotic and also transmitted from human-to-human rapidly leading to pandemic responsible for the current global health crisis. COVID-19 spreads over 221 countries and territories around the world with total confirmed cases of 130 million and 2.84 million deaths. While drugs remain under development, using conventional medicines along dietary therapy are recommended by AYUSH, Govt. of India to prevent and boost immunity to tackle SARS-CoV-2 infections. Exploration of antiviral compounds from medicinal plants to develop drugs for SARS-CoV-2 is highly warranted.

\section{Solution strategy to combat COVID-19}

The spectrum of symptoms associated with COVID-19 ranges from difficulties in breathing and other respiratory conditions to critical conditions including kidney failure, heart attack and sometimes even death and, therefore, the following strategies have been recommended to avoid spread of COVID-19.

- Avoiding International and domestic travels to spread the infection from severely affected areas/countries.

- Individuals are likely to be infected by others who have been inflicted with the virus. The disease can spread from person-to -person via small droplets from nose or mouth when a person with COVID-19 coughs or exhales; these particles in the air, settle on surfaces in the environment further infecting people who breathe these particles or touch these places and then touch their body parts, and hence 6 feet physical distance is recommended (WHO, 2020).

- Reports suggest that older persons and persons with pre-existing medical conditions (such as high blood pressure, heart disease, lung disease, cancer or diabetes) appear to develop serious illness more often than others, and hence co-morbid patients must be treated with utmost care.
- Also, it has been reported that some of the Asian populations are more susceptible to acquire this COVID-19 infection when compared to the other races populations, needs special attention.

- National Institute of Health (NIH) has mentioned that SARSCoV-2 could survive for upto $3 \mathrm{~h}$ maximum as aerosols to a maximum of three days on surfaces.

- Slowing the spread of the COVID-19 cases will significantly reduce the strain on the healthcare system of the country by limiting the number of people who are severely sick by COVID19 and need hospital care.

- So, it is time for all the citizens to join hands together to fight against coronavirus by practicing self-hygiene and physical distancing.

- WHO is coordinating efforts to develop medicines to prevent and treat COVID-19.

- India as a front runner developed an indigenous COVID vaccine COVAXIN along with COVISHIELD (the Oxford-AstraZeneca vaccine) and started vaccination campaign on $16^{\text {th }}$ January, 2021. As of $31^{\text {st }}$ March 2021, India's vaccination programme has given 65.1 million doses of vaccine with 9.3 million Indians having had two doses, and targeted to vaccinate 30 crores in near future.

7. Dietary therapy and herbal medicine could be used against COVID-19 in the following four ways

- Diet or supplement for infection prevention and immunity strengthening.

- Application as antiviral agent on masks.

- Air disinfection agent to stop aerosol transmission of the virus.

- Surface sanitizing agent to afford a disinfected environment.

\section{Conflict of interest}

The authors declare that there are no conflicts of interest relevant to this article. 


\section{References}

Achan, J.; Talisuna, A.O.; Erhart, A.; Yeka, A.;Tibenderana, J. K.;Baliraine, F.N. and D'Alessandro, U. (2011). Quinine, an old antimalarial drug in a modern world: Role in the treatment of malaria. Malaria Journal, 10(1): 144.doi:10.1186/1475-2875-10-144.

Akamatsu, H.; Komura, J.; Asada, Y. and Niwa, Y. (1991). Mechanism of antiinflammatory action of glycyrrhizin: Effect on neutrophil functions including reactive oxygen species generation. Planta Med., 57:119-121. https://doi.org/10.1055/s-2006-960045.

Al-Qahtani, A.A. (2020). Severe acute respiratory syndrome coronavirus 2 (SARS-CoV-2): Emergence, history, basic and clinical aspects. Saudi Journal of Biological Sciences, 27:2531-2538.

Arun, L.B.;Arunachalam, A.M.;Arunachalam, K.D., Annamalai, S.K. and Kumar K.A. (2014). In vivo antiulcer, antistress, antiallergic, and functional properties of gymnemic acid isolated from Gymnema sylvestre R Br. BMC Compl. Alternative. Med., 14:70. https://doi.org/ 10.1186/1472-6882-14-70.

Cao, J.; Forrest, J. C. and Zhang, X. (2015). A screen of the NIH clinica collection small molecule library identifies potential anti coronavirus drugs. Antiviral Research, 114:1-10. https://doi.org/ 10.1016/j.antiviral.2014.11.010.

Chan-Yeung, M. and Yu, W.C. (2003). Outbreak of severe acute respiratory syndrome in Hong Kong Special Administrative Region: Case Report BMJ, 326:850-852.

Chiow, K. H.; Phoon, M. C.; Putti, T.; Tan, B. K. and Chow, V. T. (2016). Evaluation of antiviral activities of Houttuynia cordata Thunb. Extract, quercetin, quercetrin and cinanserin on murine coronavirus and dengue virus infection. Asian Pacific Journal of Tropical Medicine, 9(1): 1-7. https://doi.org/10.1016/j.apjtm.2015.12.002.

Cho, J. H.; Bernard, D. L.; Sidwell, R. W.; Kern, E. R. and Chu, C. K. (2006). Synthesis of cyclopentenyl carbocyclic nucleosides as potential antiviral agents against orthopoxviruses and SARS. Journal of Medicinal Chemistry, 49(3):1140-1148. https://doi.org/10.1021/ jm0509750.

Cho, J. K.; Curtis Long, M. J.; Lee, K. H.; Kim, D. W.; Ryu, H. W.; Yuk, H. J. and Park, K. H. (2013). Geranylated flavonoids displaying SARS-CoV papain like protease inhibition from the fruits of Paulownia tomentosa Bioorganic and Medicinal Chemistry, 21(11):305-3057. https:// doi.org/10.1016/j.bmc.2013.03.027.

Cinatl, J.; Morgenstern, B.; Bauer, G.; Chandra, P.; Rabenau, H. and Doerr, H.W. (2003a). Glycyrrhizin, an active component of liquorice roots, and replication of SARS-associated coronavirus. Lancet, 361:20452046.

Cinatl, J.; Morgenstern, B.; Bauer, G.; Chandra, P.; Rabenau, H. and Doerr, H.W. $(2003 b)$. Treatment of SARS with human interferons. Lancet, 362:293-294.

Denaro, M., Smeriglio, A., Barreca, D., De Francesco, C., Occhiuto, C., Milano, G and Trombetta, D. (2019). Antiviral activity of plants and their isolated bioactive compounds: An update. Phytotherapy Research, 34(4):742-768. doi:10.1002/ptr.6575.

Donnelly, C.A.; Ghani, A.C.; Leung, G.M.; Hedley, A.J.; Fraser, C.; Riley, S.; AbuRaddad, L.J.; Ho, L.M.; Thach, T.Q.; Chau, P.; Chan, K.P.; Lam, T.H.; Tse, L.Y.; Tsang, T.; Liu, S.H.; Kong, J.H.; Lau, E.M.; Ferguson, N.M. and Anderson, R.M. (2003). Epidemiological determinants of spread of causal agent of severe acute respiratory syndrome in Hong Kong. Lancet, 361 : 1761-1766.

Drosten, C.; Günther, S.; Preiser, W.; van der Werf, S.; Brodt, H.R.; Becker, S.; Rabenau, H.; Panning, M.; Kolesnikova, L.; Fouchier, R.A.; Berger, A.; Burguière, A.M.; Cinatl, J.; Eickmann, M.; Escriou, N.; Grywna, K.; Kramme, S.; Manuguerra, J.C.; Müller, S.; Rickerts, V.; Sturmer, M.; Vieth, S.; Klenk,H.-
D.; Albert D M E Osterhaus, A. D. M. E.; Schmitz, H. and Doerr, H.W. (2003). Identification of a novel coronavirus in patients with severe acute respiratory syndrome. The New England Journal of Medicine, 348(20): 1967-1976. https://doi.org/10.1056/NEJMoa030747.

Fiore, C.; Eisenhut, M.; Krausse, R.; Ragazzi, E.; Pellati, D.; Armanini, D. and Bielenberg, J. (2008). Antiviral effects of Glycyrrhiza species. Phytother. Res., 22:141-148. https://doi.org/10.1002/ptr.2295.

Galani, V.J.; Patel, B.G. and Rana, D.G. (2010). Sphaeranthus indicus Linn.: A phyto-pharmacological review. Int. J. Ayurveda. Res., 1:247253. https://doi.org/10.4103/0974-7788.76790.

Ganjhu, R. K.; Mudgal, P. P.; Maity, H.; Dowarha, D.; Devadiga, S.; Nag, S. and Arunkumar, G. (2015). Herbal plants and plant preparations as remedial approach for viral diseases. Virus, 26(4):225-236.

Gautret, P.; Lagier, J.C.; Parola, P.; Hoang, V.T.; Meddeb, L.; Mailhe, M.; Doudier, .; Courjon, J.; Giordanengo, V.; Vieira, V.E.; TissotDupont, H.; Honore, S.; Colson, P.; Chabriere, E.; La Scola, B.; Rolain, J.M.; Brouqui, P. and Raoult, D. (2020). Hydroxychloroquine and azithromycin as a treatment of COVID-19: Results of an open-label non-randomized clinical trial. Int. J. Antimicrob. Agents, 56(1):105949.(https://pubmed. ncbi. nlm. nih.gov/32205204).

Gilani, A.H.; Khan, A.;Raoof, M.; Ghayur, M.N.; Siddiqui, B.S.; Vohra, W. and Begum, S. (2008). Gastrointestinal, selective airways and urinary bladder relaxant effects of Hyoscyamus niger are mediated through dual blockade of muscarinic receptors and $\mathrm{Ca} 2+$ channels. Fundam. Clin. Pharmacol., 22:87-99. https://doi.org/10.1111/j.14728206.2007.00561.x.

Greig, A. S. and Bouillant, A. M. (1977). Binding effects of concanavalin A on a coronavirus. Canadian Journal of Comparative Medicine, 41(1): $122-126$.

He, L.; Qi, Y., Rong, X.; Jiang, J.; Yang, Q.; Yamahara, J.; Murray, M. and Li, Y. (2011). The Ayurvedic medicine Salacia oblonga attenuates diabetic renal fibrosis in rats: Suppression of angiotensin II/AT1 signaling. Evid. Based Complement. Alternat. Med., 12.https:// doi.org/10.1093/ecam/nep095.

Ho, T. Y.; Wu, S. L.; Chen, J. C.; Li, C. C. and Hsiang, C. Y. (2007). Emodin blocks the SARS coronavirus spike protein and angiotensin converting enzyme 2 interaction. Antiviral Research, 74(2):92-101.

Hsieh, L.-E.; Lin, C.-N.; Su, B. L.; Jan, T. R.; Chen, C. M.; Wang, C. H.; Lin, D.S.; Lin, C.T. and Chueh, L. L. (2010). Synergistic antiviral effect of Galanthus nivalis agglutinin and nelfinavir against feline coronavirus. Antivir Res., 88:25-30. https ://doi.org/10.1016/ j.antiviral.2010.06.010.

Jardim, A. C. G.; Shimizu, J. F.; Rahal, P. and Harris, M. (2018). Plant derived antivirals against hepatitis c virus infection. Virology Journal, $15(34)$.

Jassim, S.A. and Naji, M.A. (2003). Novel antiviral agents: A medicinal plant perspective. J. Appl. Microbiol., 95:412-427.

Keyaerts, E.; Vijgen, L.; Maes, P.; Neyts, J. and Van Ranst, M. (2004). In vitro inhibition of severe acute respiratory syndrome coronavirus by chloroquine. Biochem. Biophys. Res. Commun., 323:264-268. https://doi.org/10.1016/j.bbrc.2004.08.085.

Keyaerts, E.; Vijgen, L.; Pannecouque, C.; Van Damme, E.; Peumans, W.; Egberink, H.; Balzarini J. and Van Ranst, M. (2007). Plant lectins are potent inhibitors of coronaviruses by interfering with two targets in the viral replication cycle. Antivir. Res., 75:179-187. https ://doi. org/10.1016/j.antiv iral.2007.03.003.

Khan, M.Y. and Kumar, V. (2019). Mechanism and inhibition kinetics of bioassay-guided fractions of Indian medicinal plants and foods as ACE inhibitors. J. Tradit. Complement. Med. 9:73-84. https:// doi.org/10.1016/j.jtcme.2018.02.001. 
Kim, D. E.; Min, J. S.; Jang, M. S.; Lee, J.Y.; Shin, Y.S.; Park, C. M.; and Kwon, S. (2019). Natural bis benzylisoquinoline alkaloids tetrandrine, fangchinoline, and cepharanthine, inhibit human coronavirus OC43 infection of MRC 5 human lung cells. Biomolecules, 9(11):696.

Kim, D.W.; Seo, K.H.; Curtis Long, M.J.; Oh, K.Y.; Oh, J.W.; Cho, J.K.; Lee, K.H. and Park, K.H. (2014). Phenolic phytochemical displaying SARS$\mathrm{CoV}$ papain-like protease inhibition from the seeds of Psoralea corylifolia. J. Enzyme Inhib. Med. Chem., 29:59-63.

Koehn, F. E.; Gunasekera, P. S.; Neil, D. N. and Cross, S. S. (1991). Halitunal, an unusual diterpene aldehyde from the marine alga, Halimeda tuna. Tetrahedron Letters, 32(2):169-172.

Ksiazek, T.G.; Erdman, D.; Goldsmith, C.S.;Zaki, S.R.; Peret, T.; Emery, S.; Tong, S.;Urbani, C.; Comer, J.A.; Lim, W.; Rollin, P.E.; Dowell, S.F.; Ling, A.E.; Humphrey, C.D.; Shieh, W.J.; Guarner, J.; Paddock, C.D.; Rota, P.; Fields, B.; DeRisi, J.; Yang, J.Y.; Cox, N.; Hughes, J.M.; LeDuc, J.W.; Bellini, W.J. and Anderson, L.J. (2003). A novel coronavirus associated with severe acute respiratory syndrome. N. Engl. J. Med., 348:1953-1966.

Kwon, H. J.; Ryu, Y. B.; Kim, Y. M.; Song, N.; Kim, C. Y.; Rho, M. C.; and Park, S. J. (2013). In vitro antiviral activity of phlorotannins isolated from Ecklonia cava against porcine epidemic diarrhea coronavirus infection and hemagglutination. Bioorganic and Medicinal Chemistry, 21(15):4706-4713. https://doi.org/10.1016/j.bmc.2013 .04 .085

Laksmiani, N. P. L.; Larasanty, L. P. F.; Santika,A. A.G. J.; Prayoga, P. A. A.; Dewi, A.A.I. K. and Dewi, N.P.A.K. (2020). Active compounds activity from the medicinal plants against SARS-CoV-2 using in silico assay. Biomed. Pharmacol. J., 13(2):873-881.

Lau, K.M.; Lee, K.M.; Koon, C.M.; Cheung, C.S.F.; Lau, C.P.;Ho, H.M., and Fung, K.P. (2008). Immunomodulatory and anti-SARS activities of Houttuynia cordata. Journal of Ethnopharmacology, 118(1):7985.

Lee, N.; Hui, D.; Wu,A; Chan, P.; Cameron, P.; Joynt, GM.; Ahuja,A.; Yung,M.Y; Leung, C.B.; To, K.F.; Lui, S.F.; Szeto, C.C.; Chung, S. and Sung, J.J. (2003). A major outbreak of severe acute respiratory syndrome in Hong Kong. N. Engl. J. Med., 348:1986-1994.

Li, SY.; Chen, C.; Zhang, H.Q.; Zhang,X.; Hua, S.; Yu, J.; Xiao, P.; Li, R. and Tan, X. (2005). Identification of natural compounds with antiviral activities against SARS-associated coronavirus. Antivir Res., 67:1823. https ://doi.org/10.1016/j.antiviral.2005.02.007.

Lin, C.W.; Tsai, F.J.; Tsai, C.H.; Lai, C.C.; Wan, L.;Ho, T.Y.; Hsieh, C.C. and Chao, P.-D. L. (2005). Anti-SARS coronavirus 3C-like protease effects of Isatis indigotica root and plant-derived phenolic compounds. Antivir. Res., 68:36-42. https ://doi.org/10.1016/j. antiviral. 2005.07.002

Lin, L. T.; Hsu, W. C. and Lin, C. C. (2014). Antiviral natural products and herbal medicines. Journal of Traditional and Complementary Medicine, 4(1):24-35

Lin, S.C.;Ho, C.T. and Chuo, W.H. (2017). Effective inhibition of MERSCoV infection by resveratrol. BMC Infect. Dis., 17:144.

Liou, C.J.; Cheng, C.Y.; Yeh, K.W.; Wu, Y.H. and Huang, W.C. (2018). Protective effects of casticin from Vitex trifolia alleviate eosinophilic airway inflammation and oxidative stress in a murine asthma model. Front. Pharmacol., 9:635. https://doi.org/10.3389/fphar. 2018.00635

Liu, Y.T.; Chen, H.W.; Lii, C.K.; Jhuang, J.H.; Huang, C.S.; Li, M.L. and Yao, H.T (2020a). A diterpenoid, 14-deoxy-11, 12-didehydroandrographolide, in Andrographis paniculata reduces steatohepatitis and liver injury in mice fed a high-fat and highcholesterol diet. Nutrients, 12:523. https://doi.org/10.3390/nu 12020523.
Liu, Z.; Xiao, X.; Wei, X.; Li, J.; Yang, J.; Tan, H.; Zhu, J.; Zhang, Q.; Wu, J. and Liu, L. (2020b). Composition and divergence of coronavirus spike proteins and host ACE2 receptors predict potential intermediate hosts of SARS-CoV-2. J. Med. Virol., https://doi.org/10.1002/ jmv. 25726.

Macintyre, G.; Curry, B.; Wong, F. and Anderson, R. (1991). Hygromycin B therapy of a murine coronaviral hepatitis. Antimicrobial Agents in Chemotherapy, 35(10):2125-2127.

Maity, N.; Nema, N.K.; Sarkar, B.K. and Mukherjee, P.K. (2012). Standardized Clitoria ternatea leaf extract as hyaluronidase, elastase and matrixmetalloproteinase-1 inhibitor. Indian. J. Pharmacol., 44:584. https:/ /doi.org/10.4103/0253-7613.100381.

McCutcheon, A.R.; Roberts, T.E.; Gibbons, E.; Ellis, S.M.; Babiuk, L.A.; Hancock, R.E. and Towers, G.H. (1995). Antiviral screening of British Columbian medicinal plants. J. Ethnopharmacol., 49:101-110.

Mishra, S.; Aeri, V.; Gaur, P.K. and Jachak, S.M. (2014). Phytochemical, therapeutic, and ethnopharmacological overview for a traditionally important herb: Boerhavia diffusa Linn. Biomed. Res. Int., 808302. https://doi.org/10.1155/2014/808302.

Moghadamtousi, S. Z.; M., Nikzad, S.; Kadir, H. A.; Abubakar, S. and Zandi, K. (2015). Potential antiviral agents from marine fungi: An overview. Marine Drugs, 13(7):4520-4538.

Nair, R. (2012). HIV-1 reverse transcriptase inhibition by Vitex negundo L. leaf extract and quantification of flavonoids in relation to anti-HIV activity. J. Cell. Mol. Biol., 10:53-59.

Neumann, H. and Neumann Staubitz, P. (2010). Synthetic biology approaches in drug discovery and pharmaceutical biotechnology. Applied Microbiology and Biotechnology, 87(1):75-86.

Oliveira,A. F. C. S.; Teixeira, R. R.; de Oliveira,A. S.; de Souza, A. P. M.; da Silva, M. L. and de Paula, S. O. (2017). Potential antivirals: Natural products targeting replication enzymes of dengue and Chikungunya viruses. Molecules, 22(3):505.

Olivieri, F.; Prasad, V.; Valbonesi, P.; Srivastava, S.;Ghosal-Chowdhury, P.; Barbieri, L.; Bolognesi, A. and Stirpe, F. (1996). A systemic antiviral resistance-inducing protein isolated from Clerodendrum inerme Gaertn. Is a polynucleotide: adenosine glycosidase (ribosomeinactivating protein).FEBS Lett., 396:132-134.

Otake, T.; Mori, H.; Morimoto, M.; Ueba, N.; Sutardjo, S.; Kusumoto, I.T.; Hattori, M. and Namba, T. (1995). Screening of Indonesian plant extracts for anti-human immunodeficiency virus-type 1 (HIV-1) activity. Phytother. Res., 9:6-10.

Oyero, O. G.; Toyama, M.; Mitsuhiro, N.; Onifade, A. A.; Hidaka, A.; Okamoto, M. and Baba, M. (2016). Selective inhibition of hepatitis c virus replication by alpha zam, a Nigella sativa seed formulation. Afr J. Tradit. Complement. Altern. Med., 13(6):144-148. doi: 10.21010/ajtcam.v13i6.20

Pandey, A.; Bigoniya, P.; Raj, V. and Patel, K.K. (2011). Pharmacological screening of Coriandrum sativum Linn. For hepatoprotective activity. J. Pharm. Bioallied. Sci., 3(3):435. https://doi.org/10.4103/ 0975-7406.84462.

Park, J. Y.; Yuk, H. J.;Ryu, H. W.; Lim, S. H.; Kim, K. S.; Park, K. H.; and Lee, W. S. (2017). Evaluation of polyphenols from Broussonetia papyrifera as coronavirus protease inhibitors. Journal of Enzyme Inhibition and Medicinal Chemistry, 32(1):504-512.

Peiris, J.S.; Chu, C.M.; Cheng, V.C.; Chan, K.S.; Hung, I.F.; Poon, L.L.; Law, K.I.; Tang, B.S.; Hon, T.Y.; Chan, C.S.; Chan, K.H.; Ng, J.S.; Zheng, B.J.; Ng, W.L.; Lai, R.W.; Guan, Y. and Yuen, K.Y. (2003a). Clinical progression and viral load in a community outbreak of coronavirus-associated SARS pneumonia: a prospective study. Lancet, 361:1767-1772. 
Peiris, J.S.; Lai, S.T.; Poon, L.L.; Guan,Y.; Yam, L.Y.; Lim, W.; Nicholls, J.; Yee, W.K.; Yan, W.W.; Cheung, M.T.; Cheng, V.C.; Chan, K.H.; Tsang, D.N.; Yung, R.W.; Ng, T.K. and Yuen, K.Y. (2003b). Coronavirus as a possible cause of severe acute respiratory syndrome. Lancet, 361:319-1325.

Poutanen, S.M.; Low, D.E.; Henry, B.; Finkelstein, S.; Rose, D.; Green, K.; Tellier, R.; Draker, R.; Adachi, D.; Ayers, M.; Chan, A.K.; Skowronski, D.M.; Salit, I.; Simor, A.E.; Slutsky, A.S.; Doyle, P.W.; Krajden, M.; Petric, M.; Brunham, R.C. and McGeer, A.J.(2003). Identification of severe acute respiratory syndrome in Canada. N. Engl. J. Med., 348:1995-2005.

Prathapan, A.; Vineetha, V.; Abhilash, P. and Raghu, K. (2013). Boerhaavia diffusa L. attenuates angiotensin II-induced hypertrophy in $\mathrm{H} 9 \mathrm{c} 2$ cardiac myoblast cells via modulating oxidative stress and downregulating $\mathrm{NF}-\kappa \beta$ and transforming growth factor $\beta 1$. Br. J. Nutr., 110:1201-1210. https://doi.org/10.1017/S0007114513000561.

Rege, A. and Chowdhary, A.S. (2014). Evaluation of Ocimum sanctum and Tinospora cordifolia as probable HIV protease inhibitors. Int. J. of Pharm. Sci. Rev. Res., 25:315-318.

Roh, C. (2012). A facile inhibitor screening of SARS coronavirus N protein using nanoparticle based RNA oligonucleotide. International Journal of Nanomedicine, 7:21-73.

Ryu, Y. B.;Jeong, H. J.; Kim, J. H.; Kim, Y. M.; Park, J.Y.; Kim, D., Naguyen, T.T.H.; Park, S.J.; Chang, J.S.; Park, K. H.; Rho, M.C. and Lee, W.S. (2010) Biflavonoids from Torreya nucifera displaying SARS-CoV 3CLpro inhibition. Bioorganic Med. Chem., 18:7940-7947. https ://doi.org/ 10.1016/j. bmc.2010.09.035.

Shen, L.; Niu, J.; Wang, C.; Huang, B.; Wang, W.; Zhu, N.; and Tan, W. (2019). High-throughput screening and identification of potent broadspectrum inhibitors of coronaviruses. Journal of Virology, 93 (12):e00023-e00019.https://doi.org/10.1128/JVI.00023-19

Sivaraman, D. and Pradeep, P.S. (2020). Revealing antiviral potential of bioactive therapeutics targeting SARS-CoV2-polymerase (RdRp) in combating COVID-19: Molecular investigation on Indian traditional medicines. Preprints, https ://doi.org/10.20944 / preprints2 $02003.0450 . v 1$.

Thayil Seema, M. and Thyagarajan, S. (2016). Methanol and aqueous extracts of Ocimum kilimandscharicum (Karpuratulasi) inhibits HIV-1 reverse transcriptase in vitro. Int. J. Pharmacogn. Phytochem. Res., 8: 1099-1103.

Tiwari, B.K. and Khosa, R.L. (2009). Hepatoprotective and antioxidant effect of Sphaeranthus indicus against acetaminophen-induced hepatotoxicity in rats. J. Pharm. Sci. Res., 1:26-30.

Tripathi, S,; Gogia, A. and Kakar, A. (2020). COVID-19 in pregnancy: A review. J. Family Med. Prim. Care, 9:4536-40.

Tsai, Y.C.; Lee, C.L.; Yen, H.R.; Chang, Y.S.; Lin, Y.P.; Huang, S.H. and Lin, C.W. (2020). Antiviral action of tryptanthrin isolated from Strobilanthes cusia leaf against human coronavirus NL63. Biomolecules, 10:366. https://doi.org/10.3390/biom 10030366

Tsang, K.W.; Ho, P.L.; Ooi, G.C.; Yee, W.K.; Wang, T.; Chan Yeung, M.; Lam, W.K.; Seto, W.H.; Yam, L.Y.; Cheung, T.M.; Wong, P.C.; Lam, B.;Ip, M.S.; Chan, J.; Yuen, K.Y. and Lai, K.N. (2003). A cluster of cases of severe acute respiratory syndrome in Hong Kong. N. Engl. J. Med., 348:19771985.
Ulasli, M.; Gurses, S. A.; Bayraktar, R.; Yumrutas, O.; Oztuzcu, S.; Igci, M.; Igci, Y.Z; Cakmak, E.A. and Arslan, A. (2014). The effects of Nigella sativa (Ns), Anthemis hyalina (Ah) and Citrus sinensis (Cs) extracts on the replication of coronavirus and the expression of TRP genes family. Molecular Biology Reports, 41(3):1703-1711. doi:10.1007/ s11033-014-3019-7.

Vellingiri, B.;Jayaramayya, K.;Iyer, M.;Narayanasamy, A.;Govindasamy, V.;Giridharan, B.;Ganesan, S.; Venugopal, A.; Venkatesan, D.; Ganesan, H.; Rajagopalan, K.; Rahman, P.K.S.M.; Cho, S.G.; Senthilkumar, N. and Subramaniam, M. D. (2020). COVID-19: A promising cure for the global panic. Sci. Total Environ.,725:138-277. https ://doi.org/10.1016/ j.scito tenv.2020.13827 7 .

Vimalanathan, S.; Ignacimuthu, S. and Hudson, J. (2009). Medicinal plants of Tamil Nadu (southern India) are a rich source of antiviral activities. Pharm. Biol., 47:422-429. https://doi.org/10.1080/13880200 902800196 .

Vlietinck, A.J. and Vanden Berghe, D.A. (1991). Can ethnopharmacology contribute to the development of antiviral drugs? J. Ethnopharmacol, 32:141-153.

Wang, S. X.; Zhang, X. S.; Guan, H. S. and Wang, W. (2014). Potential anti HPV and related cancer agents from marine resources: An overview. Marine Drugs, 12(4):2019-2035.

Wen, C. C.; Kuo, Y. H.; Jan, J. T.; Liang, P. H.; Wang, S. Y.; Liu, H. G.; and Yang, N. S. (2007). Specific plant terpenoids and lignoids possess potent antiviral activities against severe acute respiratory syndrome coronavirus. Journal of Medicinal Chemistry, 50:4087-4095. https://doi.org/10.1021/jm070295s

Wen, C.C.; Shyur, L.F.; Jan, J.T.; Liang, P.H.; Kuo, C.J.; Arulselvan, P.; Wu, J.B.; Kuo, S.C. and Yang, N. S. (2011). Traditional Chinese medicine herbal extracts of Cibotium barometz, Gentiana scabra, Dioscorea batatas, Cassia tora, and Taxillus chinensis inhibit SARS-CoV replication. Journal of Traditional and Complementary Medicine, 1(1): 41-50.doi:10.1016/s2225-4110(16)30055-4

Williamson, E. M.; Liu, X. and Izzo, A. A. (2020). Trends in use, pharmacology, and clinical applications of emerging herbal nutraceuticals. British Journal of Pharmacology, 177(6):12271240 .

Yi, L., Li, Z., Yuan, K., Qu, X., Chen, J., Wang, G., and Chen, L. (2004). Small molecules blocking the entry of severe acute respiratory syndrome coronavirus into host cells. Journal of Virology, 78(20).

Yu, M.; Lee, J. and Moo, J. (2020) Identification of myricetin and scutellarein as novel chemical inhibitors of the SARS coronavirus helicase, nsP13. Bioorganic Med. Chem. Lett., 22:4049-4054.

Yu, Y.B. (2004). The extracts of Solanum nigrum L. for inhibitory effects on HIV-1 and its essential enzymes. Korean. J. Orient. Med., 10:119-126.

Zhang, C. H.; Wang, Y. F.; Liu, X. J.; Lu, J. H.; Qian, C. W.; Wan, Z. Y.; and Li, J. X. (2005). Antiviral activity of cepharanthine against severe acute respiratory syndrome coronavirus in vitro. Chinese Medical Journal, 118(6):493-496.

Zhuang, M., Jiang, H., Suzuki, Y., Li, X., Xiao, P., Tanaka, T. and Qin, C. (2009). Procyanidins and butanol extract of Cinnamomi cortex inhibit SARS CoV infection. Antiviral Research, 82(1):73-81. 